\title{
Increased prevalence of obstructive sleep apnea in patients with Cushing's syndrome compared with weight- and age-matched controls
}

\author{
Feyzi Gokosmanoğlu', Aygül Güzel², Elif Kilic Kan'1 and Hulusi Atmaca' \\ ${ }^{1}$ Departments of Endocrinology and Metabolism, and 2Pulmonary Medicine, Faculty of Medicine, \\ Ondokuz Mayis University, Kurupelit, Samsun, Turkey
}

Correspondence should be addressed to H Atmaca

Email

mhatmaca@gmail.com

\begin{abstract}
Objective: Diabetes mellitus and obesity are well-known risk factors associated with obstructive sleep apnea (OSA). Cushing's syndrome (CS) is also characterized by obesity and diabetes mellitus. However, the association between CS and OSA remains unclear. Therefore, we investigated the possible associations between CS and OSA in this study. Patients and methods: Thirty female patients with newly diagnosed active CS and 30 age-, gender- and body mass index (BMI)-matched controls were included in this study. All participants were evaluated by overnight polysomnography. OSA was defined as having an apnea-hypopnea index (AHI) score of $\geq 5$ events/h. Insulin resistance was calculated by homeostasis model assessment (HOMA) scores. Fasting serum cortisol was also determined. Results: The prevalence of OSA was higher $(50 \%$ vs $23 \%, P=0.003)$ in patients with CS compared with the control subjects. The mean HOMA $(P=0.046)$ and $\mathrm{AHI}(P=0.028)$ scores were higher in patients with CS compared with the control subjects. AHI was positively correlated with the HOMA scores $(r=0.281, P=0.046)$ in both groups. Linear regression analysis showed that serum cortisol remained as an independent predictor for AHI after controlling for BMI and HOMA score $(P<0.001)$.

Conclusions: The prevalence of OSA increased in patients with CS compared with control subjects with similar ages and BMI levels. Hypercortisolemia is an independent risk factor for developing OSA. The presence of OSA needs to be considered in patients with CS.
\end{abstract}

\section{Introduction}

Obstructive sleep apnea (OSA) is a common chronic condition characterized by episodes of upper airway obstruction during sleep. It affects about $7 \%$ of the general population, with certain subgroups being at a higher risk (1). Apart from its well-known potential consequences, including excessive daytime sleepiness, neurocognitive deterioration and decreased quality of life, its endocrinologic and metabolic effects are becoming more recognized (2).

A number of epidemiological studies have shown that OSA is associated with a constellation of cardiovascular risk factors including central obesity, insulin resistance,

www.eje-online.org DOI: 10.1530/EJE-16-0815
() 2017 European Society of Endocrinology Printed in Great Britain impaired glucose tolerance, dyslipidemia and hypertension $(3,4,5,6)$. Cushing's syndrome (CS) is also characterized by the same comorbidities (7). As with OSA, a strong association between CS and metabolic syndrome constellations has been well known for a long time (8). However, data regarding the association between CS and OSA are scarce. Thus, there is a need to evaluate this relationship in CS, specifically in those patients in whom OSA may be underdiagnosed and undertreated.

An overnight polysomnography (PSG) is the standard diagnostic test for OSA (9). In this study, we aimed to investigate the possible relationships between CS and

Published by Bioscientifica Ltd. 
OSA. We evaluated active CS patients and compared them with age-, gender- and body mass index (BMI)-matched controls by PSG.

\section{Subjects and methods}

This study included 30 consecutive newly diagnosed and untreated female patients with CS at the Endocrinology Clinic of Ondokuz Mayss University Faculty of Medicine between January 2014 and August 2015. The control group consisted of 30 age- and BMI-matched female subjects. All patients had active clinical features consistent with Cushing's syndrome for the duration of $14.2( \pm 5)$ months.

Control subjects were not known to have diabetes mellitus prior to the study. Five of the patients with CS had diabetes mellitus, three of whom were on oral antidiabetic medication and the other two were on diet alone. Four patients with CS and six of the controls had hypertension and had been using antihypertensive medications including angiotensin-converting enzyme inhibitors, angiotensin receptor blockers or calcium channel blockers. A low-dose dexamethasone test was done to exclude CS from the controls. We excluded all other participants with medical conditions, including alcoholism, depression, smoking and any other drug use (especially glucocorticoids). Fasting blood samples were taken between 07:00 and 09:00 h for serum cortisol, glucose and insulin measurements.

Abnormal fasting glucose values were determined if a patient met the American Diabetes Association guidelines (fasting glucose $\geq 100 \mathrm{mg} / \mathrm{dL}$ ) (10). BMI of the subjects were recorded, and insulin resistance was calculated by homeostatic model assessment (HOMA) scores (11).

CS was diagnosed according to the following criteria (12): an absent cortisol suppression after a low-dose dexamethasone test $(>1.8 \mu \mathrm{g} / \mathrm{dL})$, a lack of a cortisol circadian rhythm (midnight cortisol $>7.5 \mu \mathrm{g} / \mathrm{dL}$ ) and a high 24-h urinary-free cortisol (UFC). The diagnosis of adrenocorticotropic hormone (ACTH)-dependent hypercortisolism was defined as the presence of normal or high plasma ACTH levels, cortisol suppression after a highdose dexamethasone test and pituitary adenoma on MRI. This diagnosis was confirmed by bilateral inferior petrosal sinus sampling when necessary. ACTH-independent CS was based on low plasma ACTH levels and the presence of an adrenal lesion on CT or MRI (13).

The standard all-night PSG was performed in all patients in the study. The Embla 54500 (UK) was used in the polysomnographic investigation. The PSG included eight electroencephalogram channels, electrooculogram, electrocardiogram, electromyograms of the submentalis and bilateral anterior tibialis muscles, position sensors, pulse oximetry, thermistor, nasal airflow measures and thoracic and abdominal respiratory effort sensors. Apnea and hypopnea were defined according to the American Academy of Sleep Medicine (AASM) manual scoring criteria. The apnea-hypopnea index (AHI) was calculated as the number of apnea plus hypopnea events divided by the number of hours of sleep. The severity of OSA was graded according to AASM criteria as mild $(5 \leq \mathrm{AHI}<15)$, moderate $(\leq 15 \mathrm{AHI}<30)$ and severe $(\mathrm{AHI} \geq 30)(9)$.

This study was approved by the Ethics Committee of Ondokuz Mayıs University Faculty of Medicine. All participants in the study were informed about the study, and a written consent form was read and signed by all patients.

\section{Statistical analysis}

Data analyses were performed using SPSS for Windows 17.0 (Statistical Package for the Social Science, SPSS). The mean differences in continuous data were measured by the $t$-test and the median differences of categorical data were measured by Mann-Whitney $U$ and Fisher's exact tests. Two-tailed $P$ values of $<0.05$ were considered statistically significant. Correlation analyses were performed using standard least-squares linear regression techniques for single variables and forward stepwise regression for multiple variables. Chi-square tests were used for comparing differences between categorical variables. Receiver-operating characteristics curves (ROC) were conducted when appropriate.

\section{Results}

The demographic characteristics and laboratory findings of the women with CS and the controls are shown in Tables 1 and 2 respectively. The mean age and BMI were similar in women with CS and the controls. Although fasting insulin was similar, fasting blood glucose $(P=0.028)$ and HOMA scores $(P=0.046)$ were higher in women with CS compared with the control group. Additionally, 20 (66\%) patients with CS and 12 (40\%) control subjects had impaired glucose metabolism. Of those with impaired glucose metabolism, 8 (40\%) CS patients and 6 (50\%) controls had OSA. Subjects with AHI scores greater than 15 (1 CS and 2 controls) had impaired glucose metabolism. Ten (33.3\%) CS patients and eight (26.6\%) control subjects 
Table 1 Demographic findings of patients with Cushing's syndrome $(n=30)$ and control $(n=30)$ subjects.

\begin{tabular}{|c|c|c|c|}
\hline Characteristics & $\begin{array}{l}\text { Cushing's } \\
\text { syndrome }\end{array}$ & Controls & $\begin{array}{c}P \\
\text { values }\end{array}$ \\
\hline Age $^{a}$ (years) & $45.8(19-64)$ & $44(23-63)$ & 0.567 \\
\hline $\mathrm{BMI}^{\mathrm{a}}\left(\mathrm{kg} / \mathrm{m}^{2}\right)$ & $32(25-45)$ & $33(25-45.9)$ & 0.583 \\
\hline Duration of $\mathrm{CS}^{\mathrm{b}}$ (months) & $14.2 \pm 5$ & - & - \\
\hline Subjects with IGMc & $20(66.6)$ & $12(40)$ & 0.038 \\
\hline Subjects with $\mathrm{HT}^{\mathrm{c}}$ & $10(33.3)$ & $8(26.6)$ & 0.570 \\
\hline Patients with $\mathrm{CD}^{\mathrm{c}}$ & $24(80)$ & - & - \\
\hline Patients with adrenal CS & $6(20)$ & - & - \\
\hline
\end{tabular}

${ }^{a}$ Data are medians (range), bdata are mean \pm S.D. and 'data are $n(\%)$. BMI, body mass index; CD, Cushing's disease; CS, Cushing's syndrome; $\mathrm{HT}$, hypertension; IGM, impaired glucose metabolism.

had hypertension. Regarding comorbidities, although the number of patients with hypertension was similar $(P=0.570)$ between groups, the number of patients with impaired glucose metabolism was higher $(P=0.038)$ in patients with CS compared with controls. Furthermore, although 15 patients with CS and 13 controls were postmenopausal, there were no differences in terms of menopausal stages between the groups. Of the 30 patients with CS, 24 had ACTH-secreting pituitary adenomas and 6 had cortisol-secreting adrenal adenomas.

Comparisons of groups according to the frequency and severity of OSA are shown in Fig. 1 and Table 3. Based on the PSG findings, in women with CS, the mean AHI score was higher than the control subjects $(P=0.005)$. OSA was more common and more symptomatic in women with CS compared with the control group (50\% vs $23 \%$, $P=0.003)$. Although the majority of the study population was diagnosed with mild OSA (14 patients with CS and 7 controls), only one patient with CS and 2 control subjects had moderate OSA. None of the participants had severe apnea. There was a statistically significant positive correlation between AHI index and serum cortisol levels in patients with CS $(r=0.886, P<0.001)$. The sleep apnea index was also positively correlated with the HOMA score ( $r=0.281, P=0.046)$ in both groups. We found that serum cortisol levels were a significant independent predictor

Table 2 Laboratory findings of patients with Cushing's syndrome $(n=30)$ and control subjects $(n=30)$. Data are presented as median (range).

\begin{tabular}{|c|c|c|c|}
\hline Characteristics & $\begin{array}{l}\text { Cushing's } \\
\text { syndrome }\end{array}$ & Controls & $\begin{array}{c}P \\
\text { values }\end{array}$ \\
\hline AHI (events/h) & $5(2-16)$ & $1.35(0-17.7)$ & 0.005 \\
\hline HOMA score & $2.7(1.2-14.8)$ & $2.35(2-10.2)$ & 0.046 \\
\hline Fasting glucose (mg/dL) & 109 (68-159) & 96 (69-149) & 0.028 \\
\hline Fasting insulin (U/L) & $11.6(5-46)$ & $8.65(1-32)$ & 0.117 \\
\hline
\end{tabular}

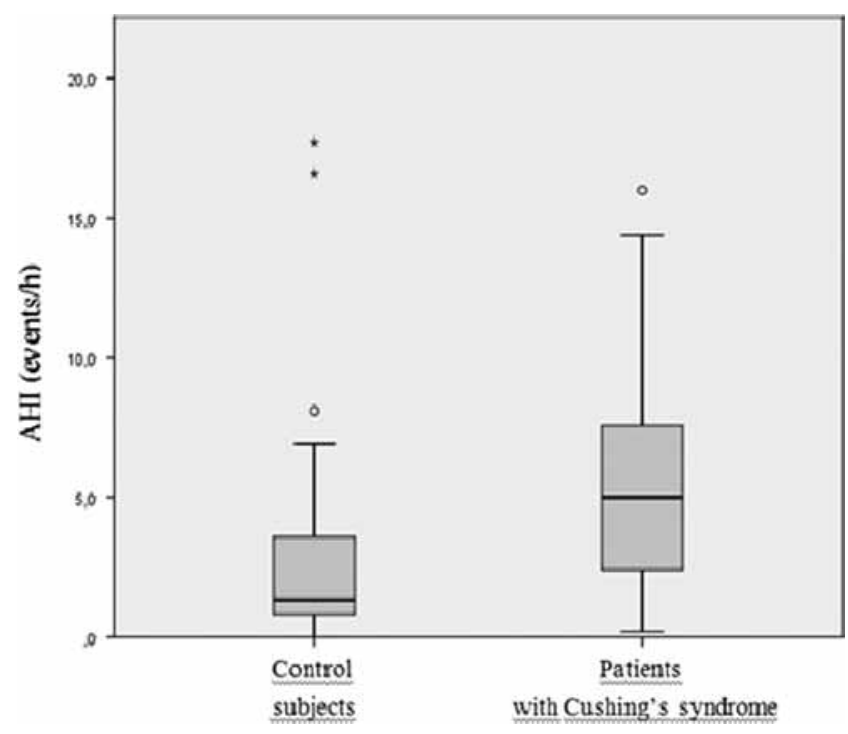

\section{Figure 1}

The apnea-hypopnea index (AHI) was higher in women with Cushing's syndrome compared with the control subjects (5 vs $1.35, P=0.005$ ).

of sleep apnea index even after controlling for BMI and HOMA scores with an adjusted $R^{2}=77.8 \%(P<0.001)$.

\section{Discussion}

In this study, the women with CS had a higher mean AHI, and the frequency of OSA was double that of the control women of similar age and BMI. Fasting serum cortisol was an independent predictor for AHI in patients with CS. Insulin resistance was also higher in patients with CS than the controls. In addition, AHI was positively correlated with HOMA scores.

The prevalence of OSA is $2-5 \%$ for adult women in the general population. However, the disease prevalence

Table 3 Comparison of groups according to the frequency and severity of obstructive sleep apnea. Data are presented as $n(\%)$.

\begin{tabular}{|c|c|c|c|}
\hline OSA & $\begin{array}{l}\text { Cushing's } \\
\text { syndrome }\end{array}$ & Control group & $P$ Values \\
\hline Subjects with OSA ${ }^{a}$ & $15(50)$ & $7(23)$ & 0.003 \\
\hline Mild OSA & $14(46.6)$ & $5(16.6)$ & 0.001 \\
\hline Moderate OSA & $1(3.3)$ & $2(6.6)$ & 0.550 \\
\hline Severe OSA & None & None & - \\
\hline
\end{tabular}

aSubjects with AHI (number of apnea/hypopnea episodes per hour) $\geq 5$; classification of OSA according $\mathrm{AHI}$ : mild, $5 \leq \mathrm{AHI}<15$; moderate, $\leq 15 \mathrm{AHI}<30$; severe $\mathrm{AHI} \geq 30$. 
is higher in obese people, older individuals and males (1). To minimize confounding factors, the study population consisted of female subjects with similar ages and BMIs. Even though OSA is generally less prevalent in women than men, the differences are diminished after the onset of menopause. This may be the result of declining estrogen and progesterone levels $(14,15)$. Accordingly, our study groups were similar in terms of premenopausal and postmenopausal stages.

Few studies have investigated the relationships between OSA and CS. In 1992, Shipley et al. evaluated 22 patients with CS by PSG and reported that 7 (32\%) patients had OSA. Of these, four patients (18\%) had severe sleep apnea (16). Our results confirm the high prevalence of OSA (50\%) in patients with active CS.

Cross-sectional surveys show that central obesity is the strongest risk factor for OSA $(17,18)$. In fact, severe OSA is present in approximately $40 \%$ of obese individuals and about $70 \%$ of OSA patients are obese (19). The absence of severe apnea in the participants could be explained by the low sample size, female sex, younger age and low BMI of this study group. Although the study groups were similar in terms of BMI, the higher frequency of OSA in the CS group must be explained by additional mechanisms. As CS patients may present with severe metabolic syndrome, it may be difficult to establish the exact role of hypercortisolism, obesity and diabetes in the onset of OSA.

In accordance with our findings, Bhushan et al. found that the AHI was positively and significantly correlated with blood glucose and HOMA scores, whereas the OSA severity was associated with increased fasting blood glucose levels and HOMA scores even after controlling for age and BMI in adolescents (20). Overall, the current evidence from cross-sectional studies strongly supports an independent association between OSA and both insulin resistance and glucose intolerance (21). Studies suggest that up to $40 \%$ of patients with OSA will have diabetes $(22,23)$. Likewise, in patients who are known to have diabetes, the prevalence of OSA may be as high as $23 \%(24)$.

CS is characterized by visceral adiposity, insulin resistance and hyperinsulinaemia (8). Glucose intolerance is seen in $20-30 \%$ of patients, and overt diabetes mellitus in $30-40 \%$ of patients with CS $(25,26)$. Based on fasting glucose levels, 20 (66\%) patients with CS, 12 (40\%) control subjects and all subjects with AHI scores greater than 15 had impaired glucose metabolism. Undoubtedly, performing oral glucose tolerance tests would increase the percentage of patients with impaired glucose metabolism and disclose patients with impaired glucose tolerance and overt diabetes mellitus more precisely.

Adiposity, particularly visceral adiposity, could still be a major confounder in these associations (21). However, recent studies have shown that the relationship between type 2 diabetes and OSA is likely to be at least partially independent of adiposity $(6,21,27)$. Apart from obesity, both sleep disruption and intermittent hypoxia can each decrease insulin sensitivity and worsen glucose tolerance by different mechanisms including sympathetic activation, hypothalamic-pituitary-adrenal axis alteration, activation of inflammatory pathways, changes in adipokine profiles and oxidative stress $(21,27,28)$.

Several factors (anatomical, functional and hormonal) may contribute to the pathophysiology of OSA in CS. Although the mechanisms of OSA in CS have never been investigated, several mechanisms can be proposed to explain how hypercortisolism causes OSA. Hypercortisolism causes an increase in HOMA scores and decreases insulin sensitivity in patients with CS, regardless of their BMI (29). In this study, we found that cortisol levels were strongly associated with AHI even after controlling for HOMA scores. This finding clearly supports the role of hypercortisolism in the pathogenesis of OSA.

There is a centripetal pattern weight gain due to adipose tissue accumulation in CS (30). It has been suggested that adipose tissue accumulation in the subcutaneous tissue of the neck, including the parapharyngeal spaces, can lead to the development of OSA in CS subjects (31). The accumulation of fat in the neck region produces a narrowing of the pharyngeal airway, thereby diminishing the passage of air (32). Greater neck circumferences are associated with both OSA and metabolic syndrome (33). Muscle weakness, which is a characteristic finding in CS, with a consequential decreased activity of the geniohyoid and genioglossus muscles, may also be responsible (34). These alterations in the upper airway could play a relevant role in OSA development, even though the pathogenesis has not been clearly specified.

Acromegaly and hypothyroidism are other endocrine and metabolic conditions associated with OSA. OSA may be improved or cured by treatment of these endocrine disorders in which OSA is mainly related to upper airway narrowing due to a reversible thickening of the pharyngeal walls (4). It would also be noteworthy to assess whether OSA is improved by the treatment of CS.

Patients with endogenous CS are at an increased risk of death from cardiovascular disease, including 
myocardial infarction, stroke and thromboembolism. In addition, cardiovascular problems, including hypertension and dyslipidemia, obesity and diabetes mellitus, and psychiatric problems including emotional lability, depression and irritability increase mortality and morbidity rates and decrease the quality of life in patients with CS $(30,35)$. There is also poorer sleep continuity, shortened rapid eye movement (REM) latency and increased first REM period density in patients with CS compared with control subjects. Therefore, the presence of sleep apnea may contribute to cognitive dysfunction in patients with CS (36). Moreover, the finding of high frequency of OSA in patients with CS should be considered a risk factor for the increased mortality and morbidity and decreased quality of life. OSA has not been recognized as a typical comorbidity of CS even in the recent literature (7). It can also be a contributory factor for the other comorbid conditions of the CS. This study will also shed light on these obscure issues.

\section{Conclusion}

The prevalence of OSA is higher in patients with CS compared with control subjects of a similar age, gender and BMI. Hypercortisolemia is an independent risk factor for developing OSA. The relative importance of fat distribution and myopathy, which are exclusive findings in CS patients, should also be investigated. In any case, the occurrence of OSA should always be considered in CS.

\section{Declaration of interest}

The authors declare that there is no conflict of interest that could be perceived as prejudicing the impartiality of the research reported.

\section{Funding}

The present study was supported by the Scientific and Technological Research Council of Turkey (TÜBITAK) (Project code no: 114S167).

\section{Acknowledgements}

The authors would like to thank Prof Dr Ramis Çolak and Prof Dr Ayşegül Atmaca for the contributions of their patients to this study.

\section{References}

1 Punjabi NM. The epidemiology of adult obstructive sleep apnea. Proceedings of the American Thoracic Society 20085 136-143. (doi:10.1513/pats.200709-155MG)

2 Zamarron C, Garcia Paz V \& Riveiro A. Obstructive sleep apnea syndrome is a systemic disease. Current evidence. European Journal of Internal Medicine 200819 390-398. (doi:10.1016/j.ejim.2007.12.006)
3 Punjabi NM, Shahar E, Redline S, Gottlieb DJ, Givelber R, Resnick HE \& Sleep Heart Health Study Investigators. Sleep-disordered breathing, glucose intolerance, and insulin resistance: the Sleep Heart Health Study. American Journal of Epidemiology 2004160 521-530. (doi:10.1093/aje/kwh261)

4 Attal P \& Chanson P. Endocrine aspects of obstructive sleep apnea. Journal of Clinical Endocrinology and Metabolism 201095 483-495. (doi:10.1210/jc.2009-1912)

5 Punjabi NM \& Beamer BA. Alterations in glucose disposal in sleepdisordered breathing. American Journal of Respiratory and Critical Care Medicine 2009179 235-240. (doi:10.1164/rccm.200809-1392OC)

6 Seicean S, Kirchner HL, Gottlieb DJ, Punjabi NM, Resnick H, Sanders M, Budhiraja R, Singer M \& Redline S. Sleep-disordered breathing and impaired glucose metabolism in normal-weight and overweight/ obese individuals: the Sleep Heart Health Study. Diabetes Care 200831 1001-1006. (doi:10.2337/dc07-2003)

7 Pivonello R, Isidori AM, De Martino MC, Newell-Price J, Biller BM \& Colao A. Complications of Cushing's syndrome: state of the art. Lancet Diabetes and Endocrinology 20164 611-629. (doi:10.1016/ S2213-8587(16)00086-3)

8 Ferrau F \& Korbonits M. Metabolic comorbidities in Cushing's syndrome. European Journal of Endocrinology 2015173 M133-M157. (doi:10.1530/EJE-15-0354)

9 Collop NA, Anderson WM, Boehlecke B, Claman D, Goldberg R, Gottlieb DJ, Hudgel D, Sateia M, Schwab R \& Portable Monitoring Task Force of the American Academy of Sleep Medicine. Clinical guidelines for the use of unattended portable monitors in the diagnosis of obstructive sleep apnea in adult patients. Portable Monitoring Task Force of the American Academy of Sleep Medicine. Journal of Clinical Sleep Medicine 20073 737-747.

10 Expert Committee on the Diagnosis \& Classification of Diabetes Mellitus. Report of the expert committee on the diagnosis and classification of diabetes mellitus. Diabetes Care 200326 (Supplement 1) S5-S20. (doi:10.2337/diacare.26.2007.S5)

11 Bonora E, Targher G, Alberiche M, Bonadonna RC, Saggiani F, Zenere MB, Monauni T \& Muggeo M. Homeostasis model assessment closely mirrors the glucose clamp technique in the assessment of insulin sensitivity: studies in subjects with various degrees of glucose tolerance and insulin sensitivity. Diabetes Care 200023 57-63. (doi:10.2337/diacare.23.1.57)

12 Nieman LK, Biller BM, Findling JW, Newell-Price J, Savage MO, Stewart PM \& Montori VM. The diagnosis of Cushing's syndrome: an Endocrine Society Clinical Practice Guideline. Journal of Clinical Endocrinology and Metabolism 200893 1526-1540. (doi:10.1210/ jc.2008-0125)

13 Newell-Price J \& Grossman AB. Differential diagnosis of Cushing's syndrome. Arquivos Brasileiros de Endocrinologia and Metabologia 2007 51 1199-1206.

14 Resta O, Bonfitto P, Sabato R, De Pergola G \& Barbaro MP. Prevalence of obstructive sleep apnoea in a sample of obese women: effect of menopause. Diabetes, Nutrition and Metabolism 200417 296-303.

15 Anttalainen U, Saaresranta T, Aittokallio J, Kalleinen N, Vahlberg T, Virtanen I \& Polo O. Impact of menopause on the manifestation and severity of sleep-disordered breathing. Acta Obstetricia et Gynecologica Scandinavica 200685 1381-1388. (doi:10.1080/00016340600935649)

16 Shipley JE, Schteingart DE, Tandon R, Pande AC, Grunhaus L, Haskett RF \& Starkman MN. EEG sleep in Cushing's disease and Cushing's syndrome: comparison with patients with major depressive disorder. Biological Psychiatry 199232 146-155. (doi:10.1016/00063223(92)90017-T)

17 Young T, Shahar E, Nieto FJ, Redline S, Newman AB, Gottlieb DJ, Walsleben JA, Finn L, Enright P, Samet JM et al. Predictors of sleepdisordered breathing in community-dwelling adults: the Sleep Heart Health Study. Archives of Internal Medicine 2002162 893-900. (doi:10.1001/archinte.162.8.893) 
18 Young T, Peppard PE \& Taheri S. Excess weight and sleep-disordered breathing. Journal of Applied Physiology (1985) 200599 1592-1599. (doi:10.1152/japplphysiol.00587.2005)

19 Wolk R, Shamsuzzaman ASM \& Somers VK. Obesity, sleep apnea, and hypertension. Hypertension 200342 1067-1074. (doi:10.1161/01. HYP.0000101686.98973.A3)

20 Bhushan B, Ayub B, Loghmanee DA \& Billings KR. Metabolic alterations in adolescents with obstructive sleep apnea. International Journal of Pediatric Otorhinolaryngology 201579 2368-2373. (doi:10.1016/j.ijporl.2015.10.046)

21 Pamidi S, Aronsohn RS \& Tasali E. Obstructive sleep apnea: role in the risk and severity of diabetes. Best Practice and Research Clinical Endocrinology and Metabolism 201024 703-715. (doi:10.1016/j. beem.2010.08.009)

22 Meslier N, Gagnadoux F, Giraud P, Person C, Ouksel H, Urban T \& Racineux JL. Impaired glucose-insulin metabolism in males with obstructive sleep apnoea syndrome. European Respiratory Journal 2003 22 156-160. (doi:10.1183/09031936.03.00089902)

23 Elmasry A, Lindberg E, Berne C, Janson C, Gislason T, Awad Tageldin $\mathrm{M} \&$ Boman G. Sleep-disordered breathing and glucose metabolism in hypertensive men: a population-based study. Journal of Internal Medicine 2001249 153-161. (doi:10.1046/j.1365-2796.2001.00787.x)

24 West SD, Nicoll DJ \& Stradling JR. Prevalence of obstructive sleep apnoea in men with type 2 diabetes. Thorax 200661 945-950. (doi:10.1136/thx.2005.057745)

25 Biering H, Knappe G, Gerl H \& Lochs H. Prevalence of diabetes in acromegaly and Cushing syndrome. Acta Medica Austriaca 200027 27-31. (doi:10.1046/j.1563-2571.2000.00106.x)

26 Krassowski J, Godziejewska M, Kurta J \& Kasperlik-Zaluska A. Glucose tolerance in adrenocortical hyperfunction. Analysis of 100 cases. Polskie Archiwum Medycyny Wewnetrznej 199492 70-75.

27 Shaw JE, Punjabi NM, Wilding JP, Alberti KG, Zimmet PZ, International Diabetes Federation Taskforce on Epidemiology \& Prevention. Sleep-disordered breathing and type 2 diabetes: a report from the International Diabetes Federation Taskforce on Epidemiology and Prevention. Diabetes Research and Clinical Practice $2008812-12$.

28 Jun J \& Polotsky VY. Metabolic consequences of sleep-disordered breathing. ILAR Journal 200950 289-306. (doi:10.1093/ ilar.50.3.289)

29 Mancini T, Kola B, Mantero F, Boscaro M \& Arnaldi G. High cardiovascular risk in patients with Cushing's syndrome according to 1999 WHO/ISH guidelines. Clinical Endocrinology 200461 768-777. (doi:10.1111/j.1365-2265.2004.02168.x)

30 Saiegh L, Sheikh-Ahmad M, Reut M, Jubran Y \& Shechner C. Challenges in the diagnosis of Cushing's syndrome in the modern era. Harefuah $2015 \mathbf{1 5 4}$ 791-794, 803.

31 Bottini P \& Tantucci C. Sleep apnea syndrome in endocrine diseases. Respiration 200370 320-327. (doi:10.1159/000072019)

32 Azagra-Calero E, Espinar-Escalona E, Barrera-Mora JM, LlamasCarreras JM \& Solano-Reina E. Obstructive sleep apnea syndrome (OSAS). Review of the literature. Medicina Oral Patologia Oral y Cirugia Bucal 201217 e925-e929. (doi:10.4317/medoral.17706)

33 Cizza G, de Jonge L, Piaggi P, Mattingly M, Zhao X, Lucassen E, Rother KI, Sumner AE, Csako G \& NIDDK Sleep Extension Study. Neck circumference is a predictor of metabolic syndrome and obstructive sleep apnea in short-sleeping obese men and women. Metabolic Syndrome and Related Disorders 201412 231-241. (doi:10.1089/met.2013.0093)

34 Rosenow F, McCarthy V \& Caruso AC. Sleep apnoea in endocrine diseases. Journal of Sleep Research 19987 3-11. (doi:10.1046/j.13652869.1998.00086.x)

35 Nieman LK. Cushing's syndrome: update on signs, symptoms and biochemical screening. European Journal of Endocrinology 2015173 M33-M38. (doi:10.1530/EJE-15-0464)

36 Shipley JE, Schteingart DE, Tandon R \& Starkman MN. Sleep architecture and sleep apnea in patients with Cushing's disease. Sleep 199215 514-518.

Received 28 September 2016

Revised version received 7 December 2016

Accepted 8 December 2016 